Encontro Nacional de

Economia Industrial e Inovação
Indústria e Desenvolvimento Econômico:

desafios e perspectivas

18 a 20 de setembro de 2018

Uberlândia - Minas Gerais

\title{
Política industrial e tecnológica, da esfera nacional à regional: padrão produtivo recente no Sul Fluminense
}

\author{
Bianca Louzada Xavier Vasconcellos ${ }^{1}$ \\ Renata Lèbre La Rovere ${ }^{2}$
}

\begin{abstract}
Áreas Temáticas:
1.4 Padrões de especialização produtiva e desenvolvimento

6.1 Políticas Industriais e Comerciais

4.2 Economias Regionais e Urbanas

Classificação JEL

R11 - Atividade econômica regional: crescimento, desenvolvimento e mudanças

O25 - Política Industrial
\end{abstract}

\section{Resumo}

Este trabalho apresenta considerações sobre os rumos da política industrial nacional, com vista ao desenvolvimento tecnológico e a importância da integração entre às esferas subnacionais. Torna-se, cada vez mais, imperativo para o desenvolvimento socioeconômico a acumulação do conhecimento, que é traduzida no avanço tecnológico e na diversificação produtiva. No entanto, o caminho para alcança-los perpassa pela adoção de políticas públicas eficientes que consigam conectar atores - públicos e privados - e regiões. O padrão produtivo atual do Sul Fluminense exemplifica as dificuldades que devem ser superadas, no âmbito da produção industrial, reprodução, difusão tecnológica e diversificação produtiva.

Palavras-chave: Política Industrial; Indústria, Tecnologia, Sul Fluminense

\begin{abstract}
This paper presents considerations about the ways of national industrial policy, with a focus on technological development and the importance of integration between the subnational spheres. It is becoming imperative for socioeconomic development the accumulation of knowledge, which leads to technological advancement and productive diversification. However, the way to achieve them is through the adoption of efficient policies that can connect actors - public and private - and regions. The current productive pattern in the region Sul Fluminense exemplifies the difficulties that must be overcome, in the context of industrial production, reproduction, technological diffusion and productive diversification.
\end{abstract}

Keywords: Industrial Policy, Manufacture, technology, Sul Fluminense

\footnotetext{
${ }^{1}$ Professora no Departamento de Economia da UFRRJ; Doutoranda no Programa de Pós-Graduação em Política Pública, Estratégia e Desenvolvimento PPED/UFRJ

${ }^{2}$ Professora no Instituto de Economia da UFRJ
} 


\section{Introdução}

A política industrial foi o cerne das políticas para o aperfeiçoamento da produção das empresas, durante o século XX. Os estruturalistas, a partir da década de 1950 cumpriram um papel importante no debate sobre a necessidade de transformação da estrutura produtiva nacional com vistas a industrialização, outrora voltada à agricultura. Conjuntamente com o modelo de substituição de importações estabeleceu-se durante longas décadas a proteção da produção nacional. Assim como Meyer-Stamer (1995) apontou para esse excesso de proteção que trouxe consequências, limitações na competitividade das empresas e no desenvolvimento tecnológico produtivo a nível internacional. O início da abertura comercial no final da década de 1980 revelou o atraso, em relação aos investimentos em pesquisa, inovação e desenvolvimento (PI\&D), por parte das empresas privadas, que se sentiam confortáveis pela baixa competitividade do mercado nacional. A concorrência e o desejo de inovar repousam sobre as empresas privadas que buscam maximização dos lucros e redução dos custos.

A partir da década de 1990, as mudanças advindas com a reestruturação produtiva da economia brasileira revelou a necessidade de políticas industriais voltadas ao desenvolvimento tecnológico. O Sul Fluminense exemplifica essas mudanças, inicialmente, como receptor de indústrias que buscavam incentivos fiscais. A ascensão neoliberal, nesse período, permitiu o ingresso de empresas multinacionais, no país, que era visto como oportunidade de catching up tecnológico. Em meio a guerras fiscais, montadoras de veículos automotores foram instaladas na porção Sul do estado do RJ, houve incremento na economia da região, no entanto, notou-se limitações para o desenvolvimento tecnológico, esbarrando no própria natureza produtiva de inserção dessas grandes empresas.

Partindo da análise de Hausmann et al (2013), que os países mais desenvolvidos são os que possuem diversificação produtiva devido ao acumulo de conhecimento, consequentemente, desenvolvimento tecnológico ao longo do tempo, se faz necessário direcionar as políticas para tal, ao mesmo tempo ligando-as às regiões que detém potenciais únicos. Nesse trabalho são discutidos caminhos para política industrial e tecnológica para economia brasileira apontando a importância da inclusão das esferas subnacionais para a implementação de políticas estratégicas e o caso do Sul Fluminense. Diante disso, o trabalho busca entender se a política industrial e tecnológica nacional está alinhada as esferas subnacionais, e consequentemente as implicações nas escolhas produtivas para região do Sul Fluminense. Para isso, o trabalho foi dividido em cinco seções, iniciando por esta introdução, o ponto dois apresenta questões sobre as mudanças ocorridas na década de 1990, com a reestruturação da indústria brasileira e seus padrões de concorrência, o terceiro tópico apresenta considerações sobre política industrial e estratégias, o quarto ponto discorre sobre política industrial e como exemplo o caso do Sul Fluminense em sua trajetória recente, por fim as considerações finais.

\section{A reestruturação da indústria e seus padrões de Concorrência}

O ambiente competitivo na década de 1980 havia um baixo grau de confiança macroeconômica, devido à instabilidade inflacionária e baixo dinamismo da economia, porém o grau de confiança microeconômica era menos desfavorável. A década de 1990 se apresentou com muita desconfiança para novos investimentos, vez que, houve uma mudança considerável de um Estado protecionista para liberal, nesse período rompeu-se com as políticas protecionistas o que acarretou em novos desafios para indústria nacional. As mudanças produtiva do período podem ser caracterizadas como "reestruturação das grandes empresas verticalizadas e rígidas, transformadas em organizações mais flexíveis e articuladas em redes, formando cadeias 
produtivas globais, afetando as relações de trabalho e as localidades onde estão instaladas. (RAMALHO E SANTANA, 2006, p. 11). No contexto do Sul Fluminense ficou claro, tais mudanças, a partir da privatização e modernização da Companhia Siderúrgica Nacional (CSN) e a chegada de investimentos no setor automobilístico. Alterações, não apenas na lógica produtiva, mas também pela entrada de um novo setor da indústria de transformação, na região.

Esse período foi caracterizado pelo processo de desconcentração produtiva, visto que ocorreu desarticulação no núcleo da indústria nacional, situada em São Paulo, segundo Canno (2005). Os ganhos de participação de outros territórios, como é o caso do Sul Fluminense, se deu pela lógica expansiva marcada pelo enfraquecimento dos laços entre os entes federativos ensejando em uma guerra de lugares, chama "guerra fiscal". Tal "embate" foi marcado por renúncias fiscais como ferramenta para atração de investimentos que, teoricamente, fomentariam o desenvolvimento regional.

Enquanto isso, no contexto econômico nacional, o ambiente competitivo entre 1990 e 1993 tiveram graus de confiança macro e microeconômicos extremamente baixos, de extrema incerteza, de acordo com Kupfer (1998). Após 1994 os resultados foram ambíguos, pois enquanto havia a estabilização monetária e melhoria na confiança macroeconômica, o próprio plano de estabilização afetava de formas negativas - taxa de câmbio valorizado e alta taxa de juros. Segundo o autor, na prática o que ocorreu foi o aprofundamento da exposição da indústria brasileira ao mercado internacional sem incorporação tecnológica por parte das empresas nacionais. Ainda que a produtividade do trabalho tenha despontado, se fez através de multinacionais e adoção de novas máquinas e equipamentos.

A estrutura do padrão de concorrência observado por Kupfer (1998) representa a formação da estrutura nacional, a indústria e setores, para os quais podem ser direcionadas políticas industriais de fomento tecnológico. Os principais setores do grupo industrial, de acordo com essa análise, são os duráveis e difusores de progresso técnico, que incorporam maior conteúdo tecnológico, encadeamento e spillovers, visto isso, uma política industrial estratégica deveria ser pensada em amplificar os potenciais que esses setores oferecem.

Kupfer (1998) caracterizou e utilizou o padrão de concorrência definido como "grupo industrial" que agrega setores com características semelhantes do padrão de concorrência, são eles: commodities (insumos metálicos, química básica, celulose e papel etc.); duráveis (automóveis e eletrônicos) que incorporam densidade tecnológica; tradicionais (indústria de alimentos e têxtil) produtos manufaturados de menor conteúdo tecnológico, bens de consumo final; difusores de progresso técnico (eletromecânicos e microeletrônicos) base do novo paradigma técnico-industrial.

O padrão de concorrência no grupo das commodities é marcado pela participação de poucas firmas, estruturas do tipo oligopólio homogêneo, com pequena diferenciação no produto e produção em escala. No padrão de concorrência dos bens duráveis é formado por poucas empresas que disputam o mercado mundial competitivamente, com progressivos avanços tecnológicos. A estrutura de mercado prevalecente é o oligopólio diferenciado e concentrado, nesse setor se desenvolveu o padrão de produção enxuta. O padrão de concorrência das indústrias tradicionais apresenta estrutura de mercado oligopolista competitivo, há grande variedade de setores devidos sua fragmentação. Segundo o autor, novas formas de articulação horizontais entre empresas começaram a ser realizados como polos regionais de produção, geradores de econômica de aglomeração. Já o padrão de concorrência dos difusores de progresso técnico sua estrutura de mercado é oligopólio competitivo, tem apoio de políticas industriais e investem continuamente em $\mathrm{P} \& \mathrm{D}$, nesse setor há concorrência por inovação. 
Partindo do pressuposto da complexidade econômica, de Hausmann et al (2013), a necessidade de diversificação e complexidade produtiva está intimamente relacionada ao desenvolvimento econômico, pois empiricamente países que apresentam maior diversificação detém maior renda per capita, que países produtores e exportadores de produtos básicos, facilmente reproduzidos. Embora o crescimento-econômico não seja único fator necessário para alcançar o desenvolvimento-socioeconômico, o segundo não será atingido sem o primeiro. Diante de todo cenário, a restruturação do setor industrial voltou-se para as vantagens do desenvolvimento do "local".

\section{Política industrial nas esferas de poder: Estratégias e prioridades}

É importante discutir política industrial por questões estratégicas formais, para que os agentes conheçam a direção das políticas que serão implantadas, Villela (1996). O autor deixa claro que a política industrial é um "projeto nacional”, e assim como mencionado por Kupfer (2013), essa política deve ser articulada com as políticas macroeconômicas, centradas na expansão e desenvolvimento. De acordo com Brandão (2012), o pensamento dominante passou a argumentar sobre o fim de escalas intermediárias, ou seja, o futuro da discussão da indústria seria direta entre o local e o global. Ainda que a maior autonomia das regiões seja uma realidade, a necessidade de interação entre as escalas não é apenas determinante, como necessária dentro de um projeto nacional.

Dessa forma, se faz necessário considerar alguns pontos que norteiam a política industrial. Para Villela (1996), o financiamento, o crédito de longo prazo, é necessário passar de crédito baseado exclusivamente no BNDES, ou seja, recursos exclusivamente públicos, para recursos de fundos privados. Ao mesmo tempo, pensar na integração entre redes internacionais, tanto exportações como investimentos, assim, entrar nas cadeias produtivas internacionais. Em relação às importações, fazer políticas moderadas de proteção tarifária, com tendência de diminuição da proteção. A capacitação tecnológica deve ser pensada em termos de sistema nacional de inovação, com a reestruturação de institutos de pesquisa tecnológica orientado a demandas do setor produtivo. Uma regulamentação mais branda e objetiva para obtenção de contratos de transferência de tecnologia seria importante para diminuir a burocracia desses acordos. O autor cita também, a importância da defesa da concorrência, como foco para as políticas industriais e a geração de competitividade. Outro ponto deve ser o apoio ao desenvolvimento de pequenas e médias empresas industriais. Segundo o autor, para que essas empresas cresçam e se integrem à economia é necessário apoio à formação de redes, isto seria possível mediante $\mathrm{SEBRAE}^{3}$ e outras entidades de desenvolvimento gerencial e capacitação. Um fator bem conhecido se refere à melhoria da infraestrutura, são eles: energia, portos, ferrovias, rodovias, aeroportos e telecomunicações. Essa estrutura é necessária para eficiência e melhoria dos serviços básicos, necessários ao bom andamento e desenvolvimento d o setor produtivo. Apena através de uma coordenação governamental eficiente e integrada será possível realizar uma política industrial eficiente.

Para o autor, o mercado interno é fundamental no traçado das políticas para que obtenham êxito. Porém, mesmo que as políticas estejam alinhadas, Villela (1996), relata que a sustentação do dinamismo potencial do mercado interno pode ser limitada por problemas conjunturais, como: a desigualdade da distribuição de renda; deficiência no sistema educacional; redução da capacidade do setor industrial gerar empregos; desequilíbrios regionais que é visto na "guerra fiscal". Ainda que a demanda interna seja fundamental na definição de políticas industriais adequadas, a integração internacional é essencial. Como a globalização da produção e geração

\footnotetext{
${ }^{3}$ Serviço Brasileiro de Apoio às Micro e Pequenas Empresas
} 
de redes internacionais; difusão de novos paradigmas tecnológicos; novas formas de proteção; formação de blocos regionais entre países para coordenação do comércio internacional.

Sobre a estratégia setorial, Villela (1996), adverte para a necessidade de uma política de competitividade nos setores difusores de progresso técnico, para "estimular a especialização setorial, e não empresarial". A proposta segue na obtenção de excelência internacional. Os setores que devem ter prioridade, segundo o autor, são: no complexo eletrônico; telecomunicações; microeletrônica; bens de capital eletromecânicos; química fina; e biotecnologias. Nesse sentido, "os instrumentos a serem utilizados são: financiamentos; uso de poder de compra preferencial; proteção tarifária mais alta; tratamento tributário e fomento as exportações das linhas de produtos selecionados." (VILLELA, 1996, p. 23). Para o autor, não significa que os demais setores devem ser deixados de lado. Ele afirma que devem ser notados setores com deficiência competitiva. E para setores competitivos as políticas devem estimular a pesquisa e o desenvolvimento de produtos.

Assim como apontado por Kupfer (2013) a política industrial não deve ser pensada em relação à intensidade de intervenção estatal, mas sim, de que forma e como se dará tal intervenção. Para Rodrik apud Gala (2017) o foco do Estado deve ser em fornecer uma política industrial dinâmica que incentive atividades, e não setores, da economia. Numa visão, nem ortodoxa, pois os mercados sozinhos não levaram ao desenvolvimento tecnológico, principalmente devido os setores que necessitam de investimentos de alto risco, nem desenvolvimentista, como foi realizada no Brasil, com forte protecionismo, pois limita o dinamismo natural da concorrência entre empresas. Segundo o autor o Estado deve ajudar o setor privado encontrar oportunidades produtivas que contribuam para o desenvolvimento.

Caberia ao Estado, segundo Rodrik, reduzir esse gap de informações e coordenação. Não se trata de selecionar vencedores. Trata-se de ajudar o setor privado a buscar novas oportunidades e fronteiras tecnológicas que possam ser eficientemente exploradas. (GALA, 2017, p. 121)

Podem ser citados, casos como os gastos militares nos EUA, que embora os investimentos sejam direcionados para o armamento bélico, a tecnologia desenvolvida acaba sendo levada para fins comerciais, para o setor aeronáutico, por exemplo. Da mesma forma a NASA, nos EUA, o Concorde na Europa, e a indústria farmacêutica, observando como o papel do Estado é fundamental para a formação das indústrias. O desenvolvimento do GPS e internet, por parte de investimentos públicos no setor militar foram, extremamente, impactantes na criação dos Smartphones, e a própria Apple. O financiamento, entre as décadas de 1950 e 1960, por parte do Pentágono no MIT, para o desenvolvimento do computador. O Estado tem um papel fundamental no investimento e financiamento de projetos de altos ricos, setores que o financiamento privado não arriscaria. No Brasil, podemos apontar o caso da Embraer, segundo o autor, como um sistema nacional de inovação. A empresa nasceu da iniciativa pública, para implantação da indústria aeronáutica no país.

A característica geográfica brasileira, de país continental, e os distintos níveis de desenvolvimento e desigualdades regionais demonstram a necessidade de se pensar política industrial e tecnológica abrangendo as esferas subnacionais. Dessa forma, Villela (1996) afirma que as regiões devem aproveitar as potencialidades locais e estimular atividades "fortes" na economia regional. $\mathrm{O}$ autor identifica as políticas frequentemente utilizadas no âmbito regional: concessão de incentivos fiscais; crédito com condições favoráveis de prazo; taxa de juros e garantias; e realização de investimentos em infraestrutura. $O$ grande problema é a falta de conexão a uma política nacional, geralmente são orientados por programas e políticas específicos. 
Destaque para a utilização de incentivos fiscais como política industrial regional, que tem sido utilizado irrestritamente por algumas regiões. Embora a "guerra fiscal" não seja algo tão recente, segundo o autor foi a partir da década de 1990, que começou a ganhar o status de "guerra". A solução para esse problema, segundo Villela (1996) seria pela reforma tributária e pela articulação de políticas regionais e estaduais com a política industrial nacional. MeyerStamer (1995), discorre que o Brasil por muito tempo deixou apenas sobre reponsabilidade da esfera federal as políticas industriais relacionadas à tecnologia, porém o autor apresenta três problemas nessa perspectiva: a capacidade do governo federal é limitada, pois as políticas são abrangentes; a economia e a sociedade são complexas, por isso, a política não deve ser centralizada no governo federal; as esferas estaduais e municipais tem um papel importante para a formulação da política tecnológica, devido o melhor conhecimento das capacidades e necessidades locais.

Por isso, torna-se essencial redefinir a divisão das tarefas entre União, estados e municípios. Sobre as multinacionais, Meyer-Stamer (1995), relata que seu comportamento advém da própria natureza delas. E afirma, que não se deve esperar que as multinacionais serão responsáveis por transferir ou compartilhar tecnologia. A abordagem de Cooke (2001) apresenta o Sistema Regional de Inovação (SRI) que é caracterizado pela combinação de elementos públicos e privados, num plano local, em nível de cidade ou distrito, com recursos de pesquisas, ao mesmo tempo articulados com as empresas locais.

(...) sintetizam a importância da dimensão local: a) existência de capacidade para o desenvolvimento do capital humano, interações entre firmas, escolas, universidades, mediadores do treinamento; b) redes formais e principalmente informais entre os membros da rede, possibilitados pelos encontros planejados ou casuais, troca de informações, relações entre vendedores e compradores (customer-supplier); c) sinergias, ou "excedente" inovativo, que podem resultar de um a cultura com partilhada, perspectivas políticas ou psicológicas resultantes da ocupação de um mesmo espaço econômico ou região; d) existência legítima de poderes estratégicos de administração em áreas tais como educação, inovação e suporte empresarial. [COOKE (1997) apud DINIZ, 2006, p.19]

Diniz (2006) propõe diretrizes para uma política tecnológica e industrial regionalizada, antes é preciso observar a dimensão territorial e aproveitar as potencialidades naturais, também é necessário que os projetos tenham um alicerce local, ou seja, utilização do conhecimento e experiência dos agentes locais. Para o autor, tal programa, deve partir da junção de dois pilares: base produtiva existente, e potencial econômico da região. A partir, da base produtiva existente será conhecido qual tipo de apoio tecnológico será enquadrado nas características setoriais da região. De maneira articulada, "o potencial produtivo de uma região deve ser analisado a partir da sua capacidade de criar vantagens comparativas construídas, pelo desenvolvimento das forças produtivas locais ou regionais.”, (DINIZ, 2006, p. 41). Sobre a identificação das prioridades da política tecnológica, visando o conhecimento local acumulado, entre empresas, universidades e órgãos governamentais. $\mathrm{O}$ autor indica que através das interações entre os agentes locais, as políticas seriam formuladas a partir do conhecimento empírico da região, com adequada avaliação das prioridades.

As estratégias políticas convergem para discussão sobre uma política industrial que visa o desenvolvimento e tecnológico. A importância da dinâmica inovativa, fomento do Estado ao setor privado e centros de pesquisas, ligando regiões a uma política central. Dessa forma, há a necessidade de se pensar numa política industrial e tecnológica em nível local/regional, já que o Brasil apresenta tantas disparidades regionais, essa também é uma estratégia para a inserção 
em cadeias globais de valor. A política local deve estar alinhada a nacional, a fim de utilizar a melhor estratégia para o desenvolvimento tecnológico e promoção do desenvolvimento socioeconômico regional.

\section{Política pública voltada à indústria: Padrão produtivo recente no Sul Fluminense ${ }^{4}$}

Nos anos 1990, o estado do Rio de Janeiro foi um dos estados que aproveitaram as oportunidades oferecidas pela política nacional e o interesse das multinacionais. Políticas como as isenções fiscais foram às primeiras medidas, uma lei de isenção total do ICMS para as empresas que investissem em novas máquinas e equipamentos. Criou-se um ambiente propício em todas as esferas administrativas, tanto a União, como o estado e municípios se empenharam de maneiras distintas e com um esforço maior por parte dos municípios, para que multinacionais se instalassem em novas localidades no estado do Rio de Janeiro.

(...) o Brasil tornou-se um importante alvo dos investimentos diretos de empresas multinacionais do setor, e graças aos incentivos fiscais de um "novo regime automotivo" esses investimentos se traduziram na construção de novas fábricas e na reestruturação das antigas com um dispêndio de mais de US\$20 bilhões. Ocorreu também um processo de reespacialização da indústria, com um deslocamento para outras regiões e municípios afastados das áreas industriais mais tradicionais, como o ABC paulista, a maioria sem relação prévia com esta atividade industrial, estimulando uma competição pelas montadoras e criando novas experiências e novos padrões de desenvolvimento local. (RAMALHO \& SANTANA, 2006, p. 16).

A política nacional visando as multinacionais automobilísticas se traduziu no "Novo Regime Automotivo" (NRA), como relata Ramalho \& Santana (2006) surgiu no mesmo período da implantação do Plano Real e tinha quatro objetivos principais: (1) preservar o funcionamento das empresas e autopeças já existentes; (2) reestruturação do setor; (3) atrair novos investimentos e plantas; (4) consolidar a posição brasileira, em relação a esse setor no MERCOSUL. Dessa forma, observou-se o uso de políticas para atração de montadoras.

Essas foram às medidas adotadas no âmbito nacional, que conjecturavam um novo ciclo industrial com mais avançada capacidade tecnológica. Cabe ressaltar o interesse das montadoras de "se mudarem" tanto de regiões que eram, fortemente, sindicalizadas, como para alterações na forma de produção, com emprego de novas tecnologias. O primeiro ponto está diretamente ligado à redução de custos, visto que, regiões com sindicatos fortes conseguiam manter certa rigidez salarial e de benefícios, como observado no interior paulista. A segunda questão faz parte da própria modernização, organização e aperfeiçoamento das fábricas e das técnicas produtivas.

Como sequência política - para o setor automotivo e seus efeitos no Sul Fluminense - deu-se continuidade com ênfase no desenvolvimento industrial e tecnológico, foi estabelecido o programa "Inovar-Auto", apresentado pela Medida Provisória 563/2012, que se converteu na Lei $\mathrm{n}^{\circ} 12.175$ de setembro de 2012, que refere-se ao Programa de Incentivo à Inovação Tecnológica e Adensamento da Cadeia Produtiva de Veículos Automotores vigorou entre janeiro 2013 e dezembro de 2017. Este programa fez parte do Plano Brasil Maior, um plano nacional que teve como objetivo investimentos para amenização dos efeitos da crise internacional de 2008. Cabe destacar que esse programa beneficiou, diretamente, todas as

\footnotetext{
${ }^{4}$ Uma das seis regiões que compõem o estado do RJ, com população de 1,06 milhão (7,1\% do estado em 2014) de habitantes, participou com 8,4\% do PIB estadual (2012).
} 
multinacionais do setor automotivo, na região Sul Fluminense. Mais adiante é apresentado as multinacionais e seus efeitos iniciais na região.

Dentre os objetivos da política estão o apoio ao desenvolvimento tecnológico, inovação, segurança, proteção ambiental, eficiência energética e qualidade dos automóveis, caminhões e autopeças. As empresas habilitadas a participar deveriam seguir algumas regras, como: produção no país de produtos classificados nas posições 87.01 a 87.06 da Tabela de Incidência do Imposto sobre Produtos Industrializados (TIPI) ${ }^{5}$, referente às peças específicas de automóveis; empresas com projeto de instalação ou já instaladas, mas com intuito de construir novas plantas. Na instauração da Lei ficava a cargo dos Ministérios do Desenvolvimento, Indústria e Comércio Exterior e da Ciência e Tecnologia, habilitar as empresas que se enquadrassem nas regras.

O foco do programa, em relação aos avanços tecnológicos, envolviam: Pesquisa básica, em atividades para desenvolvimento de conhecimento e/ou aprimoramento de novos fenômenos, para desenvolvimento de produtos, processos ou sistemas inovadores; desenvolvimento experimental, a partir, de conhecimentos pré-existentes; serviços de apoio técnico, indispensáveis à implantação e à manutenção das instalações ou dos equipamentos, à execução de projetos. Desenvolvimento de engenharia: novo produto ou processo de fabricação, novas funcionalidades, melhorias incrementais; concepção de novo produto ou processo de fabricação que implique em melhoria na produtividade; tecnologia industrial básica na aferição e calibração de máquinas e equipamentos; treinamento do pessoal dedicado à pesquisa, desenvolvimento do produto e do processo de inovação e implementação; desenvolvimento de produtos, inclusive veículos, sistemas e seus componentes, autopeças, máquinas e equipamentos; concepção, projeto, construção ou modernização de laboratório, centros de pesquisa, serviços e peças ou qualquer infraestrutura para tal finalidade; desenvolvimento de ferramental, moldes e modelos, como instrumentos e aparelhos industriais e de controle de qualidade; capacitação de fornecedores. As despesas em pesquisa, desenvolvimento tecnológico, engenharia, tecnologia industrial básica e capacitação de fornecedores deverão ser realizados, no País, pela empresa beneficiária do Inovar-auto

Existem algumas ${ }^{6}$ análises econômicas sobre os resultados de desenvolvimento tecnológico do setor automotivo referente ao Programa Inovar-Auto. Segundo Palmeri (2017) os maiores beneficiados do programa foram às empresas que se instalaram no país, que tiveram subsídios fiscais e amortizaram cerca de $98 \%$ de seus investimentos. Em seu trabalho o autor afirma que "os investimentos foram direcionados para inovação incremental e muito pouco para o desenvolvimento tecnológico nacional que era a proposta inicial” (PALMERI, 2017, p. 107). Pascoal (2015) observou os impactos da Inovar-Auto no Sul Fluminense e relata que houve falta de compreensão nas regras do programa, pouco desenvolvimento de parcerias entre fornecedores e empresas. Sobre o desenvolvimento tecnológico, na região, o auto afirma:

Os investimentos mínimos em P,D\&I exigidos pelo programa são insuficientes para recuperar a competitividade, promover um salto qualitativo em inovação e conduzir o setor a um novo patamar tecnológico comparável aos níveis de referência mundial. (PASCOAL, 2015, p. 163)

A entrada do setor no estado do Rio de Janeiro (concentrado na região Sul do estado) remota a década de 1990. Foi em 1996, que a primeira fábrica desse setor foi instalada na região - ônibus e caminhões da Volkswagen (VW) - cidade de Resende, de acordo com Ramalho \& Santana

5 A Tabela TIPI 2017 está disponível em: http://www.planalto.gov.br/ccivil 03/ato20152018/2016/decreto/Anexo/AND8950.pdf Acesso em 17/05/2018.

${ }^{6}$ LEÃO; PALMERI; GOULART 
(2006) dentre os vários fatores que colaboraram para que a empresa se instalasse na região, um dos principais pontos se deveu a posição estratégica geográfica, próxima aos principais polos produtores e consumidores do país, acessível também ao mercado sul-americano, além de não se distanciar da zona industrial do ABC paulista. A segunda montadora a se instalar no estado foi a PSA Peugeot Citroën, em 2001, também na região do MP-RJ, mais especificamente, no município de Porto Real. Essas duas empresas foram resultado de políticas de incentivos fiscais.

A inserção da VW fez crescer a expectativa em torno das atividades industriais e a sinergia que ela poderia gerar entre pequenas e médias empresas e prestadoras de serviços. Um dos fatos mais marcantes do período, de acordo com Ramalho \& Santana (2006), se refere à disputa territorial do período ocorrida pela implantação da VW. A fábrica seria alocada em terrenos que pertenciam a Porto Real (que, até então, ainda era distrito da cidade de Resende). A luta pela emancipação abriu espaço para barganhar a localização da planta da VW. Por fim, a multinacional foi estabelecida no território pertencente a Resende e Porto Real conseguiu sua emancipação.

De acordo com Oliveira (2008) essa planta causou um grande impacto sobre a reestruturação na indústria automobilística, pois a empresa empregou uma nova forma de organização da produção e trabalho. Basicamente, um sistema organizado que terceirizou toda a produção, denominado "Consórcio Modular", onde os fornecedores são organizados dentro da própria instalação da fábrica para montar o produto final. São sete empresas que trabalham como parceiras, em 2002, mantinham por volta de 1.600 empregados sem vínculos empregatícios com a VW. Porém, ligados diretamente a empresa eram por volta de 400 funcionários trabalhando na parte de gerenciamento, desenvolvimento de produtos, testes e avaliação de qualidade, como aponta Oliveira (2008). A instalação da VW refletiu no mercado de trabalho, no setor de serviços ligados ao setor automobilístico, no desenvolvimento e visibilidade da região para outras grandes empresas. Com um novo modelo de produção reestruturado fizeram notáveis investimentos em suas estruturas e em novas fábricas.

A segunda empresa a se instalar na região foi a PSA Peugeot-Citroën do Brasil se fixando em Porto Real em 2001, através de forças políticas conjuntas entre estado e município principalmente, no âmbito de concessões fiscais - embora a lógica produtiva de "fábrica enxuta" seguisse os parâmetros da VW, o modo de operação não se estabeleceu como de "consórcio modular". "A inclusão da Peugeot-Citroën do Brasil no Programa de Atração de Investimentos Estruturantes ocorreu através de lei originada no Poder Executivo Estadual e aprovada pela Assembleia Legislativa do Rio de Janeiro." (ALVAREZ, 2004, p.366). Foram utilizados recursos do FUNDES ${ }^{7}$ para efetivar o empreendimento da Peugeot, onde o governo do estado participou como investidor com porcentagem de $32 \%$ do capital da empresa até 2001. Gerou, inicialmente, mais de dois mil empregos diretos. No início, em suas instalações operavam cinco empresas, fornecedoras de equipamentos para montagem dos veículos, acarretando em uma espécie de distrito industrial.

A partir da instalação da Peugeot houve criação de um ambiente propício a novos investimentos de empresas de pequeno e médio porte, a maioria ligada ao setor automobilístico, outras devido à abertura e políticas públicas realizadas na região, que já vinha de uma tradição industrial devido principalmente a CSN, em Volta Redonda, enquanto em Resende pode-se destacar a INB (Indústrias Nucleares Brasileiras).

\footnotetext{
7 Fundo de Desenvolvimento Econômico e Social (FUNDES), destinado a financiar programas e projetos prioritários em setores estratégicos para o desenvolvimento econômico e social do Estado. DECRETO-LEI N ${ }^{\circ} 8$, DE 15 DE MARÇODE 1975. Disponível em: 〈http://www.fazenda.rj.gov.br/> acesso em 30/12/2017.
} 
Pode-se apontar algumas empresas importantes que ingressaram na região, como a fábrica de pneus da Michelin, em Itatiaia, as Indústrias Químicas Cerâmide, alocada em Resende; Indústria de Vidros Guardian, em Porto Real e a Cerâmica Unisten, em Resende. De acordo com Alvarez (2004), além das empresas do consórcio modular da MAN (que são responsáveis diretamente pela montagem), algumas empresas instalaram-se para trabalhar diretamente com as montadoras, são elas: BMB Mode Center, responsável pelo $3^{\circ}$ eixo de adaptação dos veículos da VW; Copo Fehrer, responsável pelo fornecimento de espuma para os assentos dos automóveis da Peugeot; Eurostamp, fornecedora de componentes de carroceria para a Peugeot; Faurecia, fornecimento de bancos e sistema de exaustão para a Peugeot; Gefco, operação logística da Peugeot; Vallourec, fornecedora de componentes de suspensão e eixos para a Peugeot.

O resultado das políticas de atração de multinacionais e a fixação das duas primeiras empresas colaboraram para despertar o interesse de outras fábricas. Em 2013, chegou à região a Hynduai Heavy Industries, produtora de veículos pesados está classificada dentro do cluster automotivo do Sul Fluminense. O investimento na fábrica foi de $\mathrm{R} \$ 360$ milhões com capacidade produtiva de até 5.000 unidades, como escavadeiras, retroescavadeiras e empilhadeiras. Inicialmente, contou com 1.000 trabalhadores, posteriormente manteve o funcionamento por volta dos 500 funcionários. O momento de projeção internacional e crescimento econômico do país, com a Copa do Mundo e Olimpíadas, foram determinantes para o interesse dessa empresa.

Em um curto período após a Hyundai ser instalada, já estava anunciada a implantação da Nissan, que fora inaugurada em 2014 e gerou, inicialmente, 2.000 postos de trabalho diretos e indiretos, na cidade de Resende. Sua projeção, com investimento de R $\$ 2,6$ bilhões, foi de produzir 200 mil carros por ano, abrangendo dois modelos de automóvel: o hacth New March, e o sedã Versa. Antes, esses modelos eram importados do México. Destaca-se, novamente, o incentivo fiscal por parte do estado do Rio de Janeiro e do município. Em entrevista ao Jornal O Globo, o CEO da Nissan, o brasileiro Carlos Ghosn relata o interesse da empresa no Brasil devido ao grande mercado consumidor. No ano de 2017, o presidente da empresa informou em entrevista ao Jornal Estadão a contratação de 600 funcionários e investimento de R\$200 milhões para concluir a implantação de um novo modelo, o Nissan Kicks. Mesmo com cenário de crise nacional, e enfraquecimento setorial, as previsões de longo prazo continuam otimistas, pela ampla demanda observada no país.

A última das montadoras de veículos a se alocar na região foi a Jaguar Land Rover (JLR), em 2016, no município de Itatiaia. Com investimento de $\mathrm{R} \$ 750$ milhões, a fábrica gerou 1.000 empregos diretos e indiretos, sendo 400 funcionários encarregados da produção. A empresa conta com uma parceria da rede SESI/SENAI ${ }^{8}$ para oferecer cursos profissionalizantes e preparatórios para jovens atuarem no setor automobilístico. A produção dos veículos: Range Rover Evoque e Discovery Sport, tem parceiros nacionais responsáveis pela fabricação dos bancos, vidros e sistema de escapamento, enquanto o motor é importado da Inglaterra.

Embora não haja uma parceria direta entre as multinacionais, o fato de existir mão de obra técnica qualificada, principalmente, desenvolvida no município de Volta Redonda, é um "bem compartilhado", já que diminui os custos com qualificação, embora, investimentos nessa área continuem sendo realizados. Outro fator, que todas compartilham é o momento de crise econômica, ainda assim as projeções das empresas permanecem otimistas. Enquanto a Peugeot tem um foco nas exportações para o MERCOSUL, em especial a Argentina, a Nissan vê potencial na demanda interna.

\footnotetext{
${ }^{8}$ SESI-SENAI: Serviço Social da Indústria e Serviço Nacional de Aprendizagem Industrial.
} 
Sob um ponto de vista local, o Polo Industrial do Sul Fluminense conta com um grupo de discussão liderado pela Federação da Indústria do Estado do Rio de Janeiro (FIRJAN) denominado Cluster Automotivo do Sul Fluminense e que teve início em maio de 2013 com o principal objetivo de tratar quatro temas centrais, fundamentais para o crescimento da região e para conseguir vantagens no mercado: questão energética, transporte, telecomunicações e de mão de obra. O grupo de discussão foi criado partir da iniciativa das principais empresas da região. Este propõe melhorias na qualificação de mão-de-obra com a abertura de mais vagas no curso de engenharia mecânica da Universidade Estadual do Rio de Janeiro (UERJ) e projetos de capacitação pelo SENAI.

Sobre os impactos socioeconômicos, observa-se que a mão de obra formal empregada tem importante participação no setor industrial, na região. Em algumas cidades, como Porto Real, o emprego na indústria de transformação chega a 49\%, média bem superior ao estado do RJ, com $8,9 \%$, enquanto o Brasil possui um pouco mais de $15 \%$.

Gráfico 1: Emprego formal, por atividade econômica, nos municípios e estado do RJ em 2014.

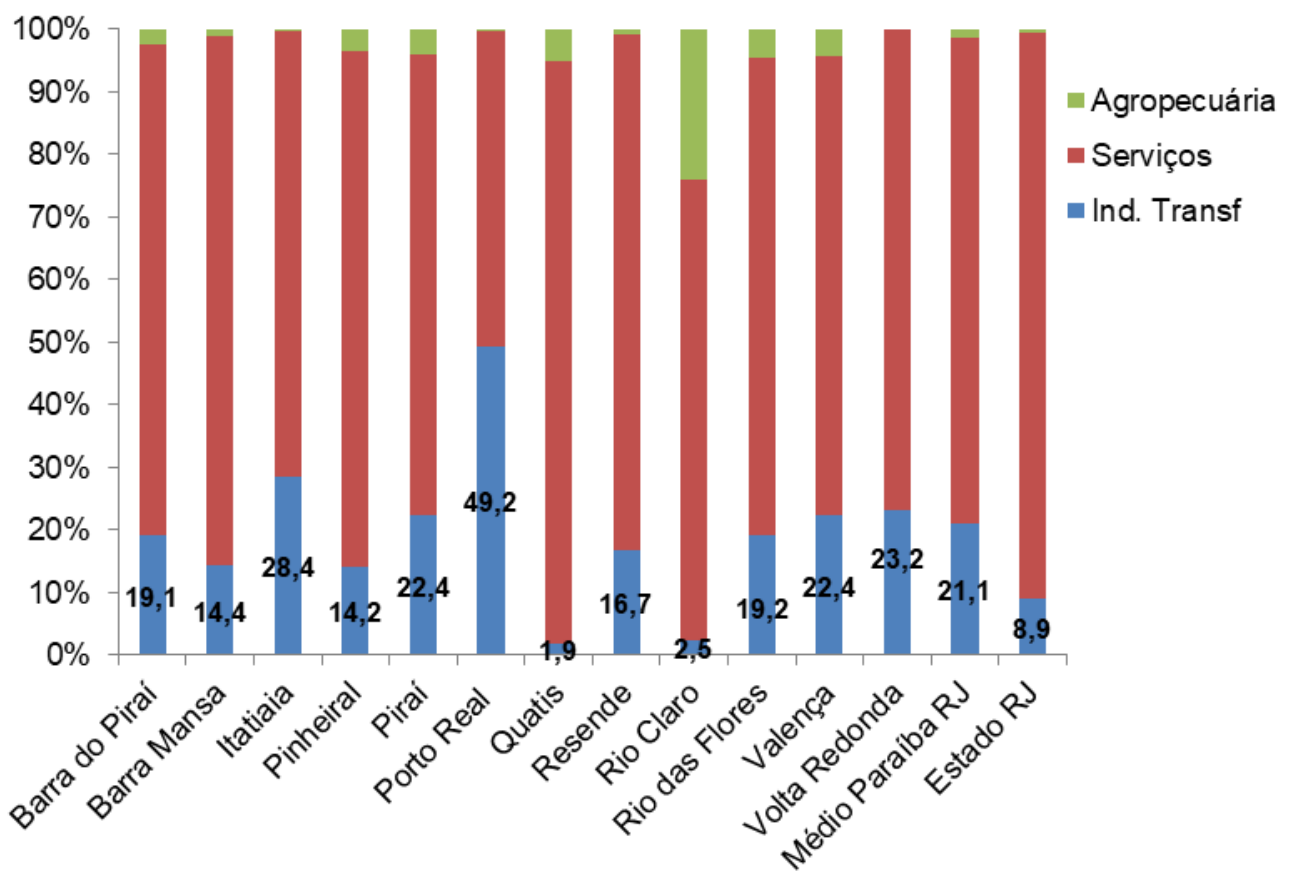

Fonte: Elaboração própria, dados do IBGE e CEPERJ/CEEP, com apoio da plataforma Data Viva.

O destaque do setor industrial na região Sul Fluminense favorece a constituição de uma rede de instituições de ensino que se aglutinam ao "redor" setor automotivo. Sobre este aspecto Cordeiro (2012) nota que a implantação destes empreendimentos têm movimentado todo o mercado de trabalho local, e, aumenta o nível de exigência de qualificação da mão de obra local. No entanto, a oferta de vagas foi incrementadas em cursos de formação, capacitação e especialização no setor industrial. A ampliação das instituições de formação da localidade seguem assim a demanda local por cursos que possibilitem uma posição dentro das novas empresas. Nesse sentido atores como o SENAI ganham destaque na formação do capital humano que busca preencher as vagas oferecidas pelas automobilísticas e suas subsidiárias. Outras instituições também ganham relevância, e, como aponta o autor surgem cursos na região que tornam-se altamente especializados para a geração de mão de obra para o cluster local.

Tendo como foco o aumento da sua "vocação industrial" a maioria dos municípios da região tem executado algumas políticas no sentido de ampliar o mercado de trabalho para a mão de obra que vem se formando nesses cursos voltados para o setor produtivo. Daí pode se ressaltar 
a relevância da participação das atividades industriais no Valor Adicionado, como a figura abaixo nos mostra:

Gráfico 2. A mão de obra na composição do VA, em cidades selecionadas do Sul Fluminense, no ano de 2014.

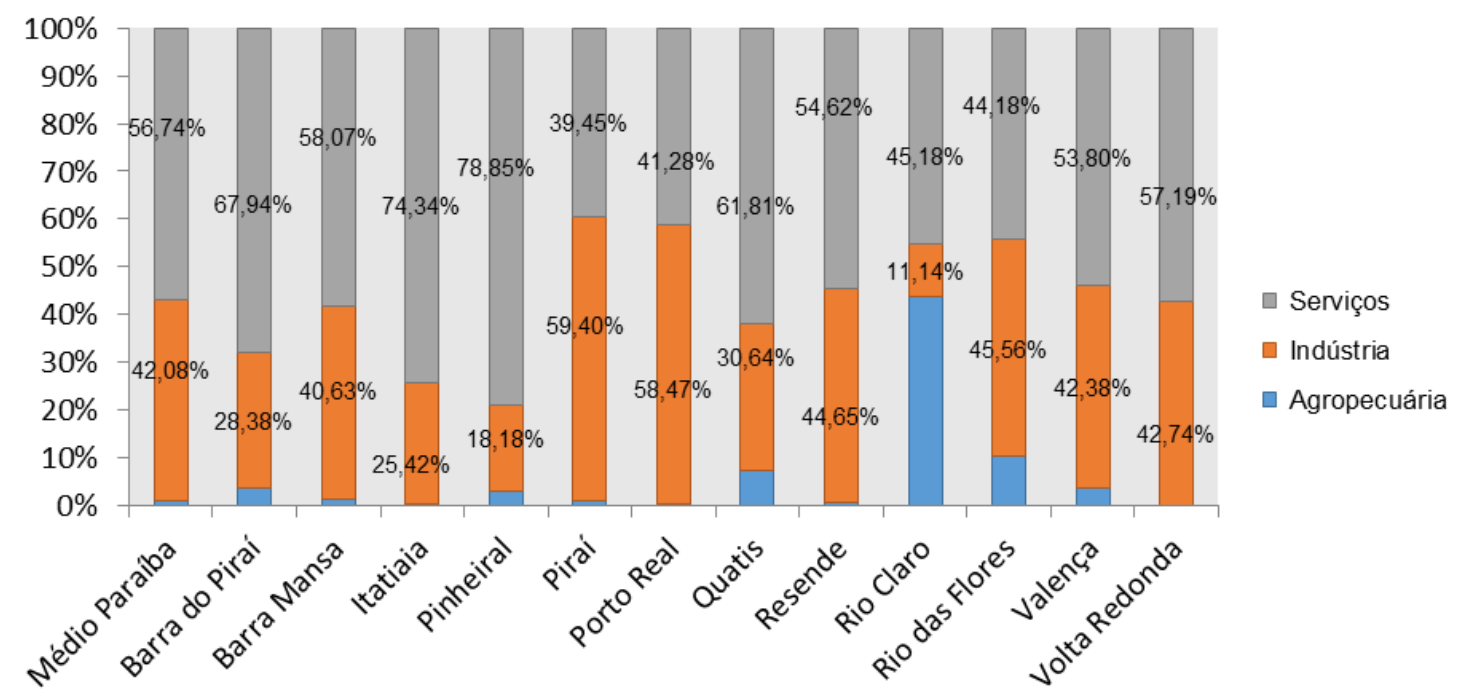

Fonte: Elaboração própria a partir de dados do IBGE e CEPERJ/CEEP .

Percebe-se assim a importância da indústria de transformação na região, o qual corresponde a alto índice de participação industrial. Cabe ressaltar que a indústria traz consigo a prestação de serviços industriais, fazendo com que o setor de serviços também cresça. O processo de atração de novas empresas e de expansão das plantas já existentes vem fomentando uma série de efeitos sobre a economia dos municípios envolvidos. No entanto, Cordeiro (2012) ressalta que a pouca organização sindical e mobilização trabalhista são características deste movimento reestruturante. As fábricas que até então estavam na Região do ABC Paulista migraram para outras localidades - ou do interior do próprio estado de São Paulo ou para outros estados - e passam a não ter mais sindicatos de classe, mas sim o que Coriat (1994) chama de "sindicatos de empresa". Que barganham os interesses da empresa junto a seus trabalhadores para se manter na localidade. Por isso, Brandão (2012) nota que com a autonomia dos locais e o aumento das disputas locacionais por novas plantas produtivas, tornam estes locais reféns das disputas por atração ou manutenção de seus investimentos.

No entanto, todo esse movimento ainda não demonstra coesão no sentido de um sistema regional de inovação. Embora exista alguma interação entre prefeituras e instituições educacionais locais ou instituições que representam o empresariado da região (SEBRAE, FIRJAN, SESI-SENAI, UERJ, AEDB ${ }^{9}, \mathrm{UFF}^{10}$, IFRJ ${ }^{11}$, ETPC ${ }^{12}$ etc.). Esse diálogo se mostra incipiente para gerar um modus operandi interligado, com parcerias que deem resultados significativos. Pensar assim na articulação de um desenvolvimento local que se faça realmente em torno de um bem comum.

\footnotetext{
${ }^{9}$ Associação Educacional Dom Bosco

${ }^{10}$ Universidade Federal Fluminense

${ }^{11}$ Instituto Federal do Rio de Janeiro

${ }^{12}$ Escola Técnica Pandiá Calógeras
} 


\section{Considerações finais}

As modificações dos padrões produtivos da econômica brasileira refletem em sua estrutura de geração tecnológica. O desenvolvimento de conhecimentos e tecnologia para o setor industrial se apresenta como chave, para participação do mercado internacional. Cabe ressaltar, a necessidade da estabilidade política e políticas macroeconômicas que fluam no mesmo sentido da política industrial. A interação entre as esferas de poder é importante e necessária via para formulação política. Observou-se o uso intensivo de incentivos fiscais que convergiu em "guerra fiscal", embora o otimismo inicial, não obteve resultados relevantes em termos de política tecnológica, nem grandes mudanças para a produção local. Infelizmente, este tipo de opção continua sendo um dos principais instrumentos políticos, utilizados indiscriminadamente, e não contribuem para crescimento da capacidade inovativa das empresas locais.

O contexto do Sul Fluminense apresenta características que podem ser exploradas, porém, ingressa na mesma lógica apontada por Meyer-Stamer (1995), em esperar uma instantânea integração entre multinacionais e a economia local. Embora, pequenos passos sejam notados como a formação técnica do IFRJ e de nível superior, pela UFF - instituições que tem desenvolvido projetos de pesquisa, participado de eventos nacionais e internacionais - assim como centros privados de formação. A dificuldade permanece na interação entre as pesquisas e os interesses do setor privado. A falta de uma instituição em nível regional, que consiga integrar todos agentes e mediar soluções restringe o potencial industrial regional. Há ainda a sensação de não pertencimento das empresas ao local.

A entrada do Sul Fluminense na cadeia global do setor automotivo revela sua posição produtiva, inserção que se dá através, basicamente, da montagem do produto final. Quando a VW deu início as suas operações, $98 \%$ de seus componentes eram trazidos de fora do estado do Rio de Janeiro. São Paulo era, e ainda é, o principal fornecedor de peças, e ainda assim, quase todo o processo de PI\&D, marketing e novos produtos são elaborados nos países sede das fábricas. Em momentos de crise aguda elas buscam assistência nas esferas do governo, nesse ponto, no fim de 2015 a preocupação por parte da população era que as empresas, simplesmente, migrassem pra outra região, que pudessem oferecer mais benefícios fiscais. Por fim, ressalta certa tendência de especialização produtiva nessa região, relegando a economia local, cada vez mais, a dependência do setor.

Esse exemplo reforça a falta de ligação a uma política nacional de estratégias para fomento tecnológico, vez que, as ligações locais-globais são correntes, o papel da política industrial e tecnológica precisa ter planejamento e metas. A diversificação produtiva dificilmente será alcançada através de empresas multinacionais implantadas no formato de "maquiladora", pelo contrário, observa-se tendência a especialização produtiva das regiões. Pois não incorporam tecnologia à indústria nacional, até o incremento de empregos fica suscetível às variações setoriais.

Um indicativo de caminho de acordo com a literatura, visto a estrutura produtiva do Sul Fluminense seria o estímulo às médias e pequenas empresas, integração com institutos de pesquisas que têm potencial interessante, estímulo a competições através do desenvolvimento de projetos em áreas chave a indústria e interesse regional, ligada a um planejamento nacional focado nas atividades que contém maior potencial para desenvolvimento tecnológico. Essas são opções de medidas para alinhamento entre política tecnológica e regional, visando o desenvolvimento da região e fomento tecnológico podem ajudar na difusão tecnológica, diversificação produtiva e fomentar os potenciais regionais. 


\section{Referências}

ALVAREZ, Roberto dos Reis. A indústria automotiva no Rio de Janeiro: uma análise da inserção dos 'fabricantes locais' de autopeças na cadeia automotiva brasileira a partir da implementação das unidades de montagem no Estado. Rio de Janeiro: Curso de Pós-Graduação em Engenharia de Produção-UFRJ. Tese de Doutorado, 2004.

BEIRA, E. J. C. Estudo e dinamização de clusters: metodologia de trabalhos. mar.2002. Disponível em: http://www3.dsi.uminho.pt/ebeira/setembro_05/wps/wp22_2002.pdf

BRANDÃO, Carlos. Território \& desenvolvimento: as múltiplas escalas entre o local e o global. Editora da UNICAMP, 2007.

BRASIL. LEI N ${ }^{\circ}$ 12.715, DE 17 DE SETEMBRO DE 2012. Institui o Programa de Incentivo à Inovação Tecnológica e Adensamento da Cadeia Produtiva de Veículos Automotores, Brasília, DF, set 2012.

CANO, W. Desequilíbrios Regionais e Concentração Industrial no Brasil: 1930-70 e 197095. Campinas, SP: Instituto de Economia - Unicamp, 1998. (30 Anos de Economia, ${ }^{\circ}{ }^{2}$ ).

CARDOSO, Cristiane. Nissan inaugura nova fábrica em Resende, RJ: Novo March foi revelado e será produzido no local com o Versa. Montadora diz que vai gerar 2 mil empregos diretos e indiretos. O Globo http://g1.globo.com/rj/sul-do-rio-costa-verde/noticia/2014/04/nissaninaugura-nova-fabrica-em-resende-rj.html> Acesso em: 23/07/2017

CASSIOLATO, José Eduardo; LASTRES, Helena Maria Martins. Sistemas de inovação e desenvolvimento: as implicações de política. São Paulo em perspectiva, v. 19, n. 1, p. 34-45, 2005.

COOKE. Regional Innovation Systems, Clusters, and the knowledge economy. Industrial and Corporate Change. 2001.

CORDEIRO, M. de C. Trabalhadores-estudantes: estudar e trabalhar, ou estudar para trabalhar? Uma análise da relação entre trabalho e educação no sul fluminense. Enfoques - Revista dos alunos do PPGSA-UFRJ. v. 11, n. 1. 2012. p. 133-159.

CORIAT, B. Pensar Pelo Avesso. Rio de Janeiro: Revan, 1994.

Data Viva. Disponível em: < https. http://dataviva.info > Acesso em 20/07/2017.

Diário do Vale, Hospital Regional funcionará em março. Disponível em http://diariodovale.com.br/politica/hospital-regional-funcionara-em-marco/ Acesso em 29/01/2018

DINIZ, Clélio Campolina. Globalização, escalas territoriais e política tecnológica regionalizada no Brasil. CEPAL/IPEA, 2006.

FERREIRA, ANDRÉ. Desenvolvimento Regional: Limites e Possibilidades Institucionais-Um Estudo de Caso da Região do Vale do Paraíba-RJ. Rio de Janeiro, 2012. 
GALA, Paulo. Complexidade Econômica: Uma nova perspectiva para entender a antiga questão da riqueza das nações. Rio de Janeiro: Contraponto: Centro Internacional Celso Furtado de Políticas para o Desenvolvimento, 2017.

GUIMARÃES, Fábio Celso de Macedo Soares. A política de incentivo à inovação: inovação, desenvolvimento econômico e política tecnológica. Parcerias Estratégicas, v. 5, n. 9, p. 121128, 2010.

HAUSMANN, R. et al. The Atlas of Economics Complexity - Mapping Paths to prosperity. The MIT Press, London, England:, Cambridge, Massachusetts. 2013.

IBGE - Instituto Brasileiro de Geografia e Estatísticas. IBGE Cidades. Resende/Porto Real. Disponível em: < http://www.cidades.ibge.gov.br/> Acesso em 20 de maio de 2014

Jaguar Land Rover. Depois de 25 anos no país, a jaguar land rover inaugurou em Itatiaia, interior do rio de janeiro, sua primeira fábrica fora do reino unido. Disponível em: <https://www.landrover.com.br/fabrica/index.html > Acesso em 25/07/2017.

KUPFER, David. Trajetórias de Reestruturação da indústria brasileira após a abertura e a estabilização Tese de Doutorado, cap. 3. UFRJ. 1998

KUPFER, David, HASENCLEVER, L.Economia Industrial. Fundamentos Teóricos e Práticas no Brasil. Rio de Janeiro: Editora Campus, Cap 24, 2013.

LASTRES, H. M. M.; CASSIOLATO, J. E. Systems of innovation, clusters and industrial districts: analytical and policy implications of convergence and differences in the approaches. 3rd Globelics Conference South Africa, Pretoria, 1 November 2005a.

Glossário de Arranjos e Sistemas Produtivos e Inovativos Locais, nov 2004. Disponível em: http://www.desenvolvimento.gov.br/arquivos/dwnl_1289323549.pdf

Novas Políticas na Era do Conhecimento: o foco em arranjos produtivos e inovativos locais, fev. 2003a. Disponível em:

http://www.ie.ufrj.br/redesist/Artigos/LasCasParcerias.pdf

Políticas para promoção de arranjos produtivos locais de micro e pequenas empresas: conceito de vantagens e restrições dos equívocos usuais, mai. 2003b. Disponível em: http://www.redesist.ie.ufrj.br.

LEÃO, Carina; GOULART, Letícia. O Inovar-Auto e os investimentos em P\&D no setor automotivo. 2012.

LIMA, Pedro Garrido da Costa. EVOLUÇÃO RECENTE DA INDÚSTRIA AUTOMOTIVA. Brasília: Câmara dos Deputados, 2016. Disponível em: < http://www2.camara.leg.br/acamara/documentos-e-pesquisa/estudos-e-notas-tecnicas/areas-da-

conle/tema10/2016_14309_evolucao-recente-da-industria-automotiva_pedro-garrido > Acessado em 06/09/2017

MEYER-STAMER, Jörg. . New Departures for Technology Policy in Brazil, Science and Public Policy, vol.22, n.5, pp.295-304,1995. 
Nissan. Complexo industrial de Resende monta primeira carroceria do crossover Nissan Kicks. Disponível em: <https://www.nissan.com.br/experiencia-nissan/noticias-e-eventos/complexoindustrial-de-resende-monta-primeira-carroceria-do-crossover-nissan-kicks.html Acesso em 25/07/2017.

OEC. Exportação de carros em 2016. Disponível em <http://atlas.media.mit.edu/pt/visualize/tree_map/hs92/export/show/all/8703/2015/ Acesso em 25/07/2017.

OLIVEIRA, Floriano José Godinho de. Reestruturação produtiva, território e poder no Rio de Janeiro. Rio de Janeiro: Garamond, 2008.

PALMERI, Nivaldo Luiz. O impacto do programa Inovar-Auto na indústria automotiva brasileira. São Paulo, UNIP. Tese de Doutorado, 2017.

PASCOAL, Erik Telles. NOVO REGIME AUTOMOTIVO BRASILEIRO: DESAFIOS E OPORTUNIDADES DA REGIÃO SUL FLUMINENSE. Tese de Doutorado. UNESP, Guaratinguetá. 2015. Disponível em: https://repositorio.unesp.br/bitstream/handle/11449/132217/000852625.pdf?sequence=1\&isAl lowed=y > Acesso em 09/09/2017.

PAULA, Esdras Kênia de. Pólo Automotivo Sul Fluminense: novos rumos para o desenvolvimento econômico da região. 2015. 190 f. Dissertação (Mestrado) - Curso de Políticas Públicas, Estratégia e Desenvolvimento, Ufrj, Rio de Janeiro, 2015.

PEREIRA, Luiz Felipe. Jaguar Land Rover inaugura fábrica em Itatiaia, RJ. O Globo. Itatiaia, 2016. Disponível em <http://g1.globo.com/rj/sul-do-rio-costa-verde/noticia/2016/06/jaguarland-rover-inaugura-fabrica-em-itatiaia-rj.html> Acesso em 25/07/2017.

RAMALHO, José Ricardo; SANTANA, M. A. (orgs) Trabalho e Desenvolvimento Regional: Efeitos Sociais da indústria automobilística no Rio de Janeiro. Rio de Janeiro: Mauad X, 2006.

SACHS, I. Desenvolvimento includente, sustentável sustentado. Rio de Janeiro: Garamond, 2004.

SALLOWICZ, Mariana. Nissan vai contratar 600 funcionários e criar segundo turno em fábrica no Rio. O Estadão. São Paulo. Disponível em: < http://economia.estadao.com.br/noticias/negocios,nissan-vai-contratar-600-funcionarios-ecriar-segundo-turno-em-fabrica-no-rio,70001677421 >. Acesso em: 23/07/2017

SCRIVANO, Roberta. Volkswagen vai investir R\$ 1,5 bilhão na fábrica de caminhões de Resende: Recurso será usado entre 2017 e 2021 em novos produtos e modernização da produção. O Globo https://oglobo.globo.com/economia/volkswagen-vai-investir-15-bilhao-nafabrica-de-caminhoes-de-resende-20573378>. Acesso em: 23/07/2017

VILLELA, Annibal V.; SUZIGAN, Wilson. Elementos para discussão de uma política industrial para o Brasil. Brasília, Texto para discussão No 421, IPEA,1996. 